\title{
5. NATURAL GAMMA-RAY MEASUREMENTS ON ODP CORES: INTRODUCTION TO PROCEDURES WITH EXAMPLES FROM LEG $150^{1}$
}

\author{
B.W. Hoppie, ${ }^{2}$ P. Blum, ${ }^{3}$ and Shipboard Scientific Party ${ }^{4}$
}

\begin{abstract}
We present procedures for the acquisition of natural gamma-ray (NGR) data from the newly installed multisensor track (MST) NGR apparatus, along with several applications of Leg 150 data that demonstrate the usefulness of this tool. Our results indicate that MST NGR data should well serve its intended purposes of providing (1) reliable core-log correlation, (2) intersite and regional stratigraphic correlation, and (3) data for lithologic studies.

NGR analysis is a function of the random and discrete spontaneous decay of radioactive atoms, the types and concentrations of radioactive elements present, detector type and geometry, and the time period of the analysis; we discuss each of these parameters in detail. Based on data collected during Leg 150, we recommend subtracting approximately 9 counts per second of background radiation for MST NGR data, using $30 \mathrm{~s}$ or longer counting periods, sampling 30 - to 40 -cm increments, and applying an empirical volumetric correction we derive herein. These parameters were found to produce a statistically significant, high-resolution NGR record that is consistent among cores and sites.

Finally, we use a limited set of MST NGR and downhole Schlumberger natural gamma-ray tool (NGT) data to derive a function for fitting the counting units of the MST NGR to the American Petroleum Institute (API) units of the NGT. Application of the function to MST NGR data shows excellent agreement with NGT logs from Holes 904A, 905A, and 906A. Corrected and calibrated MST NGR data also show possible intersite correlations between Holes 903C and 903D, from which downhole NGT data were not obtained. MST NGR data, as shown in an example from Hole 906A, also improves upon NGT data in the shallow portions of holes normally covered by surface casing before downhole logging.
\end{abstract}

\section{INTRODUCTION}

On ODP Leg 149, a new multisensor track (MST) device for measuring the emission of natural gamma rays (NGR) of recovered cores was installed aboard the JOIDES Resolution. On Leg 150, we took NGR measurements of terrigenous sediment cores from four sites and examined a number of factors relevant for evaluation and comparison of core measurements with downhole natural gamma-ray tool (NGT) logs. The purpose of this account is to introduce the new device as an integral part of shipboard instrumentation, provide an overview of the principles involved in NGR measurements and correlation of core and downhole logs, and give some examples from Leg 150; we do not put NGR measurements into the context of the Leg 150 scientific objectives.

Addition of the NGR apparatus to the MST represents a return of NGR measurements on cores to scientific ocean drilling. A very similar apparatus was used during early DSDP legs; a first account is found in the reports of DSDP Leg 2 (Evans and Lucia, 1970) and the last account to our knowledge is in DSDP Leg 11 (Paulus, 1972). According to ODP sources, the original NGR device was removed from the Glomar Challenger sometime near Leg 30 . The apparent reason for its removal was the excessive counting time needed for useful NGR logs. Results from the new NGR device during Leg 150 were good to excellent at all sites and are discussed herein.

NGR scans were desired by parts of the scientific community during the early DSDP to relate NGR logs of core segments to corresponding downhole logs. This was considered especially important because holes were not continuously cored during DSDP; furthermore, even if continuous coring was attempted, recovery was far from complete. Therefore, log-lithology interpretation based on correlation of cored intervals was the main purpose (Evans and Lucia,

\footnotetext{
${ }^{1}$ Mountain, G.S., Miller, K.G., Blum, P., et al., 1994. Proc. ODP, Init. Repts., 150: College Station, Texas (Ocean Drilling Program).

${ }^{2}$ Earth Sciences Department, University of California, Santa Cruz, CA 95064, U.S.A

${ }^{3}$ Ocean Drilling Program, 1000 Discovery Drive, College Station, TX 77845, U.S.A.

${ }^{4}$ Shipboard Scientific Party is as given in the list of participants preceding the Table of Contents,
}

1970). Paulus (1972) showed that some unconformities and layers of environmental significance could be detected best with NGR scans. Evans and Lucia (1970) and Paulus (1972) thought that useful total count logs could be retrieved without introducing excessive counting times, whereas recording of NGR spectra would have to be conducted mostly on shore (Evans and Lucia, 1970). Leg 150 results complement these views, and we will only briefly discuss the potential of spectral gamma-ray measurements.

The new device on the JOIDES Resolution is principally the same as the one on the Glomar Challenger, except that modern digital data acquisition and display replaced the chart recorders (a detailed description is given in a later section). The return of NGR measurements on cores may largely be the result of vast improvements in data acquisition, processing, and the increasing amount of acquired data. As core recovery and the quality of downhole logs improved, the desire for integration of core and downhole data also increased. NGT downhole logs have long been used to integrate different downhole logging data sets in a hole or across holes. It was time for a renewed call for a core-NGR device to allow core-core and core-downhole log correlation. The JOIDES Shipboard Measurement Panel spearheaded the initiative, and ODP constructed and installed the apparatus between 1991 and March 1993.

\section{PRINCIPLES OF NATURAL GAMMA-RAY MEASUREMENTS}

\section{Concepts of NGR Radiation}

Natural radioactivity is the result of the random and discrete spontaneous decay of atoms. The decay is accompanied by emission of alpha $(\alpha)$ or beta $(\beta)$ particles, gamma $(\gamma)$ rays, and generation of heat. Gamma radiation may be considered as an electromagnetic wave similar to visible light or X-rays, or as a particle or photon emitted from an atomic nucleus during radioactive decay. Its characteristic wave length is $10^{-10}$ to $10^{-12} \mathrm{~cm}$.

In contrast to $\alpha$ and $\beta$ particles, $\gamma$-rays have a high power of penetration and therefore serve as a basis for downhole and core logging techniques. The probability of emission depends on the num- 
ber of atoms of the radioisotope: the higher this number, the higher is the probability of emission. For a collection of $N$ identical radioactive particles, the number of atoms decaying per unit time will be

$$
d N / d t=-\lambda N,
$$

where $\lambda$ is the decay or disintegration constant. The exponential relation between $N$ and $t$ is

$$
N=N_{0} \exp (-\lambda \mathrm{t})
$$

where $N_{0}$ is the number of atoms present at $t=0$.

At every instant, the rate of decay is $\lambda N$. This rate, also known as the activity $(A)$, also follows an exponential decay law:

$$
A=\lambda N=\lambda N_{0} \exp (-\lambda t)
$$

The unit of activity is the curie, which is defined as $3.7 \times 10^{10}$ disintegrations per second. The curie is defined in terms of the number of decaying nuclei and not in the number of emissions.

\section{Use of NGR}

NGR logs are mainly used for three purposes: (1) correlation of core and/or downhole data sets in single or multiple holes, (2) evaluation of shale content of a formation, and (3) mineral analyses. The first two goals can be achieved by simply measuring total counts of the formation. Mineral analysis is a more sophisticated and problematic process that requires spectral logging.

The radioisotopes with sufficiently long life, and whose decay produces an appreciable amount of gamma-rays are (a) potassium $\left({ }^{40} \mathrm{~K}\right)$, with a half-life of $1.3 \times 10^{9} \mathrm{yr}$; (b) thorium $\left({ }^{232} \mathrm{Th}\right)$, with a half-life of $1.4 \times 10^{10} \mathrm{yr}$; and (c) uranium $\left({ }^{238} \mathrm{U}\right)$, with a half-life of 4.4 $\times 10^{9} \mathrm{yr}$. The principal rocks containing these radioisotopes are clays and shales, which by one means or another fix K, U, and Th. Other examples include arkosic silt and sandstones, potassium salts, bituminous and alunitic schists, phosphates, certain carbonates, some coals, and acid or acido-basic igneous rocks (Serra, 1984).

\section{Natural Gamma-ray Spectrometry (NGS)}

The gamma-rays emitted from the three main radioisotopes $\mathrm{K}$, Th, and $U$ have a number of discrete energies. Each series has a spectral signature that enables its presence to be discerned. Characteristic peaks are at $1.46 \mathrm{MeV}$ for ${ }^{40} \mathrm{~K}, 2.62 \mathrm{MeV}$ for ${ }^{232} \mathrm{Th}$, and $1.76 \mathrm{MeV}$ for the ${ }^{238} \mathrm{U}$ series. Numerous other peaks exist for ${ }^{232} \mathrm{Th}$ and ${ }^{238} \mathrm{U}$. The relative amplitudes of the three spectra will depend on the proportions of the radioactive components present, so that a quantitative evaluation of the presence of $\mathrm{K}$, Th, and $\mathrm{U}$ can be obtained by dividing the total spectrum into the three characteristic spectra. This analysis will be valid because the Th and $U$ series are normally in a state of secular equilibrium and each series has a characteristic spectrum.

The three high-energy peaks of $\mathrm{K}$, Th, and $\mathrm{U}$ represent only about $10 \%$ of the total spectrum in terms of counting rates. About $90 \%$ of the counts come from the low-energy part of the spectrum, which is degraded by Compton scattering; they can be retrieved and used for more accurate computation of the $\mathrm{K}$, Th, and $\mathrm{U}$ contents. To accomplish this, a set of equations is written as follows:

$$
W_{i}=A_{i} \mathrm{Th}+B_{i} \mathrm{U}+C_{i} \mathrm{~K}+r_{i},
$$

where $r_{i}$ is a factor representing the statistical errors, $W_{i}$ is the count rate from a predetermined energy window (see "Equipment" section, this chapter), and $A_{i}, B_{i}$, and $C_{i}$ are the calibration coefficients derived empirically. The equations are then solved by the least-squares method, minimizing $r^{2}$, which is the sum of all $r_{i}^{2}$. To decrease the effects of anticorrelation between $\mathrm{Th}$ and $\mathrm{U}$ and negative readings caused by statistical variations, a Kalman filter can be applied (Serra, 1984).

The MST NGR apparatus is capable of acquiring spectral data for calculating elemental yields of ${ }^{40} \mathrm{~K},{ }^{232} \mathrm{Th}$, and ${ }^{238} \mathrm{U}$. However, because test cores with known concentrations of ${ }^{40} \mathrm{~K},{ }^{232} \mathrm{Th}$, and ${ }^{238} \mathrm{U}$ do not presently exist, we were unable to calibrate the apparatus. Thus, although we acquired spectral data at Sites 903 and 906, we were unable to calculate ${ }^{40} \mathrm{~K},{ }^{232} \mathrm{Th}$, and ${ }^{238} \mathrm{U}$ concentrations.

\section{Units and Standard Calibration}

Gamma radioactivity is expressed either in $\mu \mathrm{g}$ Ra equivalent/metric ton, or in GAPI (Gamma-ray, American Petroleum Industry) units. All commercial NGR logs, including the Schlumberger NGT logs generated during ODP operations, are reported in GAPI units. The GAPI unit is defined at a calibration pit at the University of Houston, Texas. The pit consists of three zones of specific mixtures of Th, U, and $\mathrm{K}$, two of low activity, and one of high activity (Belknap et al., 1959). A GAPI is an arbitrary unit of measure defined as $1 / 200$ of the deflection measured between the high and low activity zones in the calibration pit. This scale is chosen for convenience; limestones have readings of 15-20 GAPI, whereas shales vary from 75 to 150 GAPI, with maximum readings of about 300 GAPI for very radioactive shales (Dewan, 1983). In addition to the NGT tool master calibration in the test pit, secondary calibrations are conducted in the field. Similar procedures, albeit at a different test pit, are followed for the calibration of natural gamma spectroscopy (NGS) tools.

\section{Factors Affecting NGR Responses}

Vertical resolution is the minimal depth increment, or layer thickness, that can be defined by adjacent samples of statistically significant, averaged NGR counts. Resolution is determined by the sensor efficiency, the activity and concentration of the material measured, the volume of influence, the counting time required for a statistically valid count, and the logging speed or sampling increment.

The response of gamma-ray tools is a function of the concentration of the radioactive mineral in the formation, and the bulk density of the sediment or rock. Although bulk density generally varies by less than a factor of 2 in the natural materials we are concerned with, concentrations of radioactive material may vary by an order of magnitude (e.g., clay-rich vs. carbonate-rich material). Radioactive phenomena are random in nature (i.e., subject to statistical variations). Count rates vary about a mean value, and counts must accumulate over a period of time and be averaged to obtain a reasonable estimate of the mean. For random statistical variations, $50 \%$ of the sampled data will lie within $\pm 0.67 N /(2 N T)^{1 / 2}$, the probable error, where $T$ is the time constant and $N$ is the mean count rate (Dewan, 1954, in Serra, 1984). Thus, the time constant, as used in downhole logging, refers to the time over which counts are accumulated and averaged. For a given count rate, the probable error decreases with increasing time constant.

Critical factors affecting resolution are volume and geometry of the formation to be measured, and geometry of the sensors. Downhole NGR sensors measure radioactivity from a "sphere" of influence around the sensor, with the diameter of the sphere being the limiting factor of the tool's intrinsic resolution. The diameter of the sphere depends on the energy levels of the radioactive isotopes and the formation density, and is approximately 0.5 to $1.0 \mathrm{~m}$ for terrigenous sediments; $90 \%$ of the contributing radioactivity comes from within a diameter of 0.2-0.4 m (e.g., Wahl, 1983; Dewan, 1983; Desbrandes, 1968 , in Serra, 1984).

For continuously sampled cores or downhole formations, vertical resolution $(R)$ can be expressed as the product of logging speed $(v)$ and time constant $(\mathrm{T})$, or $R=v \mathrm{~T}$. The minimum resolved thickness $R$ can be decreased by decreasing logging speed or time constant. For practical purposes, logging speed cannot be reduced indefinitely; a 
typical logging speed is $1800 \mathrm{ft} / \mathrm{hr}(15.24 \mathrm{~cm} / \mathrm{s})$. The time constant, at a given logging speed, can only be reduced as far as low-activity materials are still represented by statistically valid average counts. For downhole logging, typical time constants are 2 to $4 \mathrm{~s}$. For $v=$ $15.24 \mathrm{~cm} / \mathrm{s}$ and $\mathrm{T}=3 \mathrm{~s}$, the vertical resolution is about $46 \mathrm{~cm}$. The NGR log will not accurately represent the radioactivity of material contained in a bed thinner than this interval of maximum resolution.

At present, MST NGR measurements are not made on the moving core. Instead, the core is moved through the device and stopped at user-defined sampling increments; samples are then taken at userdefined counting periods. Logging speed and time constant, therefore, cannot be directly related to those of the downhole logs; however, the measure of vertical resolution is directly comparable. A reasonable sampling increment, such as $46 \mathrm{~cm}$ (downhole NGT resolution; Borehole Research Group, 1990) or $30 \mathrm{~cm}$ (size of the MST NGR sample chamber; see "Sampling Volume" section, this chapter) is programmed with the main MST sensors control interface. Counting times must then be chosen so as to provide statistically significant count averages comparable to those obtained from downhole logging.

\section{EQUIPMENT}

NGR tools consist of gamma-ray detector(s) and associated electronics for passing the gamma-ray count rate to the recording interface. Practically all gamma-ray tools, including those used in ODP, use scintillation detectors. The scintillation counter contains a doped sodium iodide $(\mathrm{NaI})$ crystal and a photomultiplier to produce countable pulses. When a gamma-ray strikes the crystal, a single photon of light is emitted which strikes a photocathode made from cesium antimony or silver magnesium. Photons hitting the photocathode release bundles of electrons, which are accelerated in an electric field to strike a series of anodes of successively higher potential. A final electrode conducts a small current through a measure resistor to give a voltage pulse, signaling that a gamma ray struck the $\mathrm{NaI}$ crystal. The tool response depends on two factors: (1) detector efficiency or sensitivity (i.e., the number of gamma rays detected per unit concentration), and (2) energy response of the detector (i.e., the resolution and conversion slope of volts input vs. output).

All detector and electronics components of the new MST NGR device were supplied by EG\&G ORTEC, Inc. (Fig. 1A. ). The apparatus was assembled on the JOIDES Resolution in March 1993. It contains four $3 \times 3$ in. $(7.6 \times 7.6 \mathrm{~cm})$, cylindrical $\mathrm{NaI}$ scintillation detectors, each housed with a photomultiplier in copper tubing. The detectors are arranged at $90^{\circ}$ angles from each other in a plane orthogonal to the core track. Detectors and sample chamber are shielded from external (cosmic) gamma radiation by lead rings and plates recovered from the previous DSDP NGR device (Figs. 1B. and 2). The computer interfaces consist of analog-to-digital converters. The peak height of each pulse is measured and stored in the appropriate one of 2048 channels; this and the EG\&G MAESTRO graphical software interface running on a dedicated PC allow for spectral gamma-ray analyses.

A directly interfacing data acquisition program customized by ODP collects counts in five energy windows that correspond to the Schlumberger downhole NGT windows; the sum of the windows is the total count. The entire sampled spectrum lies between 200 and $3000 \mathrm{keV}$. Window 1 (200-499 keV) measures the high-count, lowenergy spectrum containing several uncharacteristic emission peaks of both ${ }^{232} \mathrm{Th}$ and ${ }^{238} \mathrm{U}$, as well as several of their daughter products. Window $2(500-1099 \mathrm{keV})$ also has high counts and contains several emission peaks of both ${ }^{232} \mathrm{Th}$ and ${ }^{238} \mathrm{U}$ and their daughter products. Window 3 (1100-1589 keV) has dramatically reduced NGR counts and contains the only emission energy peak of ${ }^{40} \mathrm{~K}$ (near $1460 \mathrm{keV}$ ). It also holds several emission energies of ${ }^{232} \mathrm{Th}$ and ${ }^{238} \mathrm{U}$. Window 4 (1590-1999 keV) contains the characteristic emission energy of ${ }^{238} \mathrm{U}$ but has few NGR counts and is therefore most susceptible to background radiation. Window $5(2000-3000 \mathrm{keV})$ contains the highest energies measured and the characteristic emission of ${ }^{232} \mathrm{Th}$.
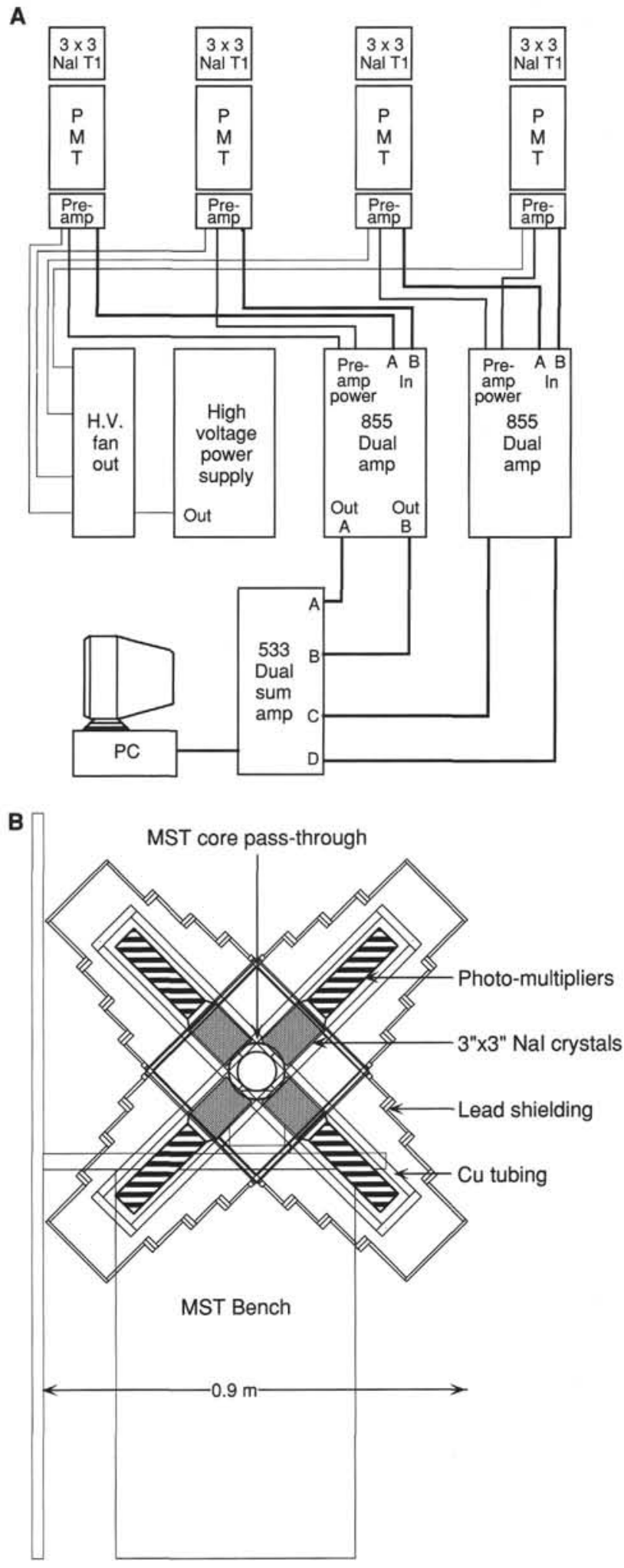

Figure 1. Schematic of new MST NGR device on the JOIDES Resolution. A. Electrical components and connections. B. Geometrical configuration (cross section). 


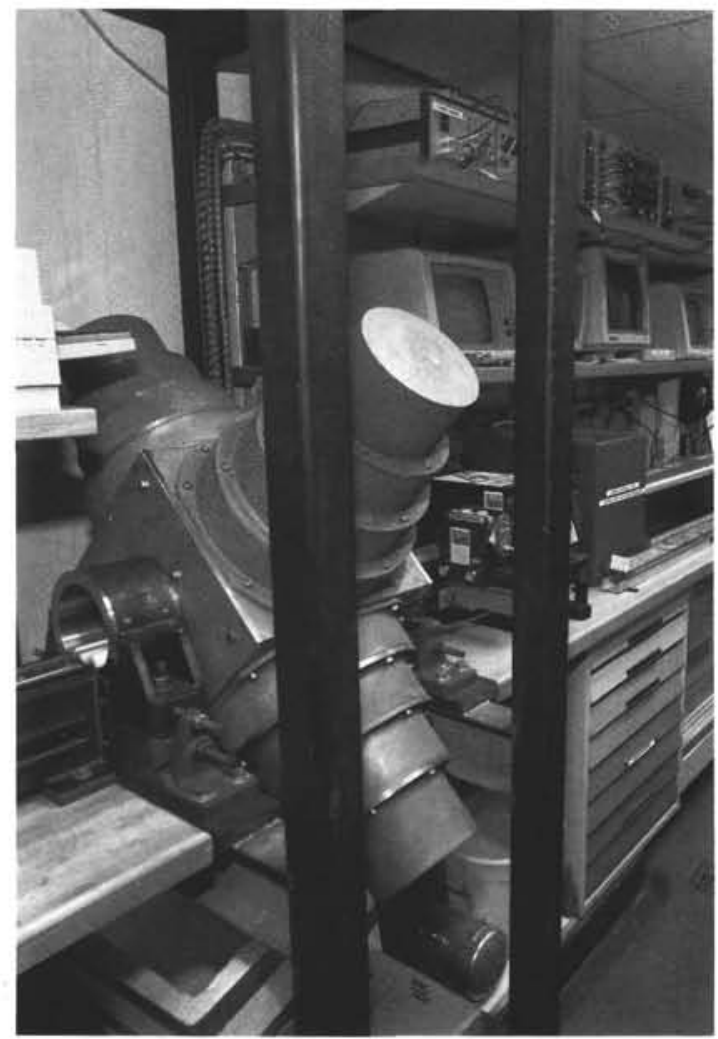

Figure 2. MST NGR device on the JOIDES Resolution.

Two calibration steps, which are less important for total count measurements but may be significant for spectral analysis, should be required from the user on a routine basis: (1) MAESTRO software calibration and (2) sensor calibration. The software calibration uses a Europium spectrum measured by ODP personnel and stored in the MAESTRO spectra library; the two characteristic peaks of 121.78 $\mathrm{keV}$ and $1480.65 \mathrm{keV}$ were assigned to channels 95 and 993, respectively. This setting will not change as long as it is left alone by the user. At the beginning of each leg, shipboard scientists should verify that the peaks are still assigned to the channel numbers. The MST software uses this setting to calculate energies from channel numbers.

The sensor calibration is necessary to make sure that events of corresponding energy detected by the four sensors are counted by similar channels. Using a potassium source, the MAESTRO graphical user interface should show the one and only characteristic peak at $1.46 \mathrm{MeV}$ (plus low energy counts). If more than one peak is displayed, the detector output of each sensor needs to be adjusted to fall into the correct channels. This is accomplished by disconnecting three of the four sensors and adjusting the gain on the amplifier for the connected one, and checking the count display again. This is then repeated for the other sensors. This procedure ensures good resolution of the characteristic peaks of accumulated counts and accurate count distribution in the spectral windows.

After calibration has been performed, or parameters have been checked and calibration found to be unnecessary, a standard core section should be run and a calibration record added to the data file directory.

\section{MST NGR OPERATIONAL PARAMETERS}

The foregoing principles of NGR measurement show that deriving an internally consistent and physically meaningful gamma-ray log is a function of (1) the contribution of background radiation, (2) the volume of scanned sample, (3) the counting period, and (4) the sam- pling increment of the test. We will now use data collected on Leg 150 to define these parameters for the MST NGR device.

\section{Background Radiation}

We made over 100 manual measurements of background radiation routinely between 26 June and 22 July 1993 . The average of these data is 9 counts per second (cps), with a standard deviation of $0.6 \mathrm{cps}$; no secular variations were present.

Background radiation varied slightly with the positioning of the core within the detector. The gamma-ray attenuation porosity evaluator (GRAPE) apparatus, which uses a radioactive cesium source, is located approximately $60 \mathrm{~cm}$ from the center of the NGR sample chamber and apparently contributes a small amount of radiation to the NGR. Tests blocking the NGR entrance (near the GRAPE) with a nonradioactive test core filled with laboratory quality $\mathrm{CaCO}_{3}$ reduced the background radiation by up to $0.3 \mathrm{cps}$. Analysis of the background radiation spectrum using EG\&G ORTEC MAESTRO software showed several poorly defined ${ }^{137} \mathrm{Ce}$ emission peaks. We could not ascertain whether this resulted from the proximity of the GRAPE source or whether the peaks are simply part of the ambient background radiation.

The GRAPE does not appreciably irradiate samples before they are taken. Our tests with sections of $\mathrm{CaCO}_{3}$ and $\mathrm{KCl} / \mathrm{BaSO}_{4}$ showed no statistical variation in their gamma radioactivity when passed through the GRAPE before undergoing NGR analysis or inserted into the opposite side of the MST NGR.

\section{Sampling Volume}

Because NGR tests are often performed on cores with voids, narrow diameters, or near the end of a section, volumetric corrections must be made to normalize the MST NGR record and create consistent output. Previously, Paulus (1972) noted similar problems with the DSDP apparatus but did not offer a correction.

Void, end-of-section, and narrow-diameter effects reduce detected NGR emissions primarily by reducing the volume of material scanned. Furthermore, gamma radiation falls off exponentially from its source (cf. Hearst and Nelson, 1985; Rider, 1986) and thus the distribution of radial and axial void-space within the testing chamber also becomes a prominent concern. We chose to correct edge and narrow-diameter effects together without deconvolving the combined effects of variable volume and distribution of gamma-ray sources from the detectors.

Our correction is an empirical relationship based on numerous scans of our $\mathrm{KCl} / \mathrm{BaSO}_{4}$ test-core at varying distances from the center of the sample chamber. We first defined the axial distance scanned by the MST NGR apparatus during each test by placing our test core incrementally closer to the scintillating detectors until the measured signal became larger than the background radiation of $9.0 \pm 0.6 \mathrm{cps}$. This distance, the axial scan interval of one MST NGR test, is between 12 and $14 \mathrm{~cm}$ fore and aft of the center of the sample chamber. Radially, the entire $6.6 \mathrm{~cm}$ diameter of the core is scanned.

These axial and radial dimensions yield a core volume within the testing device of approximately $1000 \mathrm{~cm}^{3}$ and correspond to a scan in which there were no edge or narrow-diameter effects. Next, we sequentially reduced this total volume by placing variable volumes of test core at variable distances from the center of the sample chamber and recorded the corresponding NGR signals. These data, which represent effects produced by reduced sample volumes, are presented in Figure 3. If we assume that the concentration of NGR-emitting materials in core are evenly distributed, then a simple empirical correction may be drawn from these data:

$$
\begin{gathered}
\mathrm{NGR}_{\mathrm{c}}=\mathrm{NGR}_{\text {une }} d\left(3.7878-1.0047 \times V_{s}+0.0564 \times\right. \\
\left.V_{s}^{2}-0.0004 \times V_{s}^{3}\right),
\end{gathered}
$$




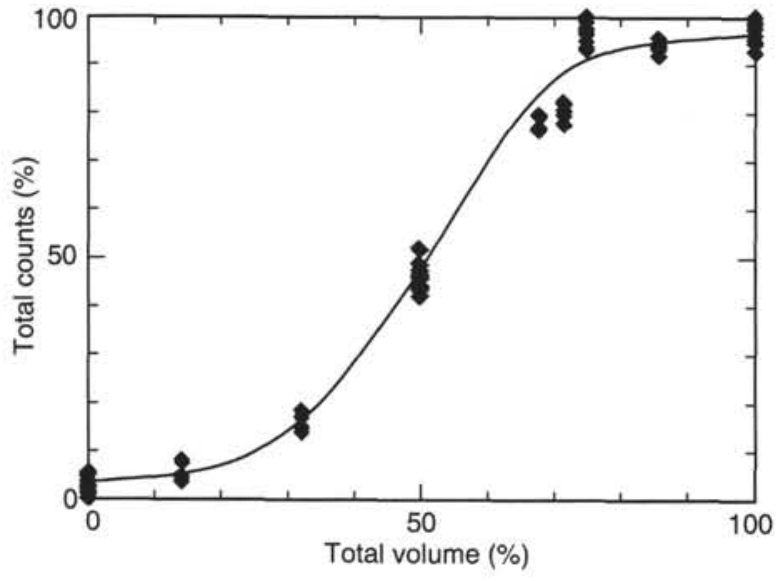

Figure 3. NGR variation as a function of sample volume for the MST NGR apparatus. The total volume measured at any time is approximately $1000 \mathrm{~cm}^{3}$.

where

$\mathrm{NGR}_{\mathrm{c}}=$ corrected NGR in cps,

$\mathrm{NGR}_{\text {unc }}=$ uncorrected $\mathrm{NGR}$ in $\mathrm{cps}$ with background radiation removed, and

$V_{s}=$ core sample volume as a fraction of core liner volume within testing device.

Equation 1 requires the independent estimation of $V_{s}$ within the sample chamber at the time of the NGR test. For applications shown later in this paper, we used core photographs and the Leg 150 core summary reports to estimate this volume.

Application of Equation 1 assumes that the effect of gamma-ray detection fall-off away from the center of the sample chamber is minimal compared to the loss of sample volume, that formations are homogeneous over the length of the sample chamber, and that coring fluids in voids contribute negligible gamma radiation. For core examined during Leg 150, these assumptions all seemed reasonable.

\section{Counting Periods}

Because gamma-ray emissions are random and discrete events, proper temporal and spatial sampling intervals must be defined before sampled materials can be accurately characterized. Inadequate sam- pling intervals can distort the shape of NGR variations and lead to improper assessment of the gamma radioactivity of the sampled materials (Rider, 1986). This is a well-known problem with downhole gamma-ray logging where logging companies have established parameters for consistent and accurate NGR evaluation procedures (Serra et al., 1980).

Table 1 summarizes the results of our tests to optimize MST NGR counting periods. The deteriorating precision of NGR tests with shorter testing periods (column 1) is evident from the increasing percent of the total signal which lies within one standard deviation of the mean (column 5). This error becomes unacceptable in certain lithologies like the Eocene chalks recovered during Leg 150 where NGR emissions were as low as $10 \mathrm{cps}$ and trends developed over 2-3 $\mathrm{cps}$ ranges. If NGR counting periods in this chalk were conducted for only $10 \mathrm{~s}$, the combined statistical errors of background $(0.6 \mathrm{cps})$ and sample $(1.1 \mathrm{cps})$ radiation would approximately equal the observable range of NGR variations and thus render the data useless. Similar problems related to short counting periods would be likely in other low gamma-radioactive lithologies like pelagic cherts and limestones (cf. Paulus, 1972).

Most analyses during Leg 150 were conducted over $30 \mathrm{~s}$ as this time allowed for minimum statistical imprecision $(5.6 \%$; cf. Table 1$)$ without slowing the process of core testing.

\section{Sampling Increments}

The sampling increment of the MST NGR device should be designed to (1) match the resolution of downhole NGT logs; (2) identify thin, highly radioactive horizons (i.e., ash beds) that provide good regional correlation; and (3) characterize mineralogical variations in thin (i.e., $<1 \mathrm{~m}$ ) horizons.

At Hole 904A, we varied our sampling interval to assess the impact of different sampling intervals on NGR resolution. Comparisons of the MST NGR and downhole NGT signals (Fig. 4) show that NGR resolution from tests of 1 measurement per $1.5 \mathrm{~m}$ section produced a smooth NGR curve that fails to record several subtle NGR variations recorded in the downhole logs (Fig. 4A). The sampling interval of $20 \mathrm{~cm}$ shows good resolution (Fig. 4B); however, our test interval only overlapped with downhole logs for $10 \mathrm{~m}$. Sampling every $40 \mathrm{~cm}$ also shows good resolution and agrees well with the resolution of downhole logs (Fig. 4C; Serra et al., 1980).

It may be possible to use a shorter sampling increment (i.e., $<30$ $\mathrm{cm}$ ) than we chose for Leg 150 to characterize some very thin (i.e.,
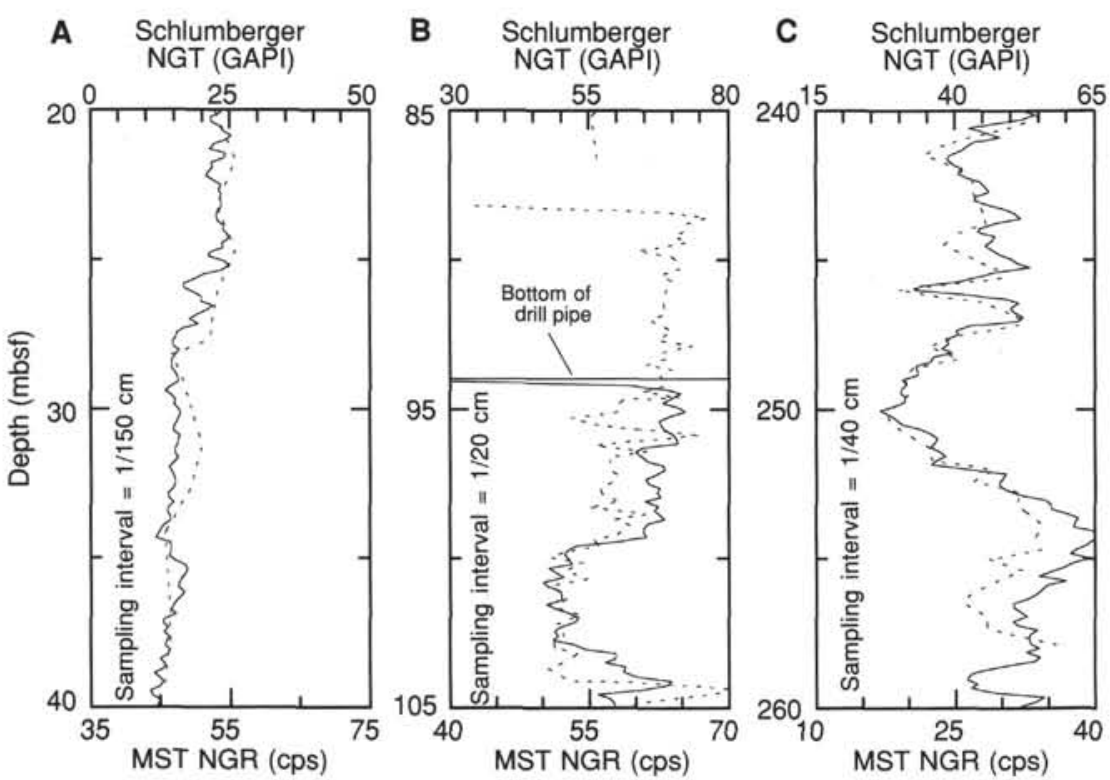

Figure 4. Three different MST NGR sampling intervals (dashed lines) compared to correlative downhole gamma-ray logs (solid lines) from Hole 904A. A. Interval from 20 to $40 \mathrm{mbsf}$ in which MST NGR tests were conducted every $150 \mathrm{~cm}$. B. Interval from 85 to $105 \mathrm{mbsf}$ in which measurements were taken every 20 $\mathrm{cm}$. C. Portions of interval where measurements were taken every $40 \mathrm{~cm}$. 
Table 1. NGR counting statistics for selected test periods during Leg 150.

\begin{tabular}{crrrr}
\hline $\begin{array}{c}\text { Test } \\
\text { period } \\
(\mathrm{s})\end{array}$ & $N$ & $\begin{array}{c}\text { Mean NGR } \\
\text { signal } \\
\text { (counts) }\end{array}$ & $\begin{array}{c}\text { SD } \\
\text { (counts) }\end{array}$ & $\begin{array}{c}\text { SD } \\
(\%)\end{array}$ \\
\hline 10 & 10 & 86.1 & 9.6 & 11.2 \\
20 & 10 & 181.1 & 13.5 & 7.4 \\
30 & 10 & 286.4 & 16.1 & 5.6 \\
60 & 10 & 549.4 & 28.3 & 5.2 \\
120 & 9 & 1081.4 & 35.3 & 3.3 \\
\hline
\end{tabular}

Note: Mean NGR signal, in total counts, includes background radiation contributions. $N=$ number of tests.

$<30 \mathrm{~cm}$ ) stratigraphic horizons. Vertical resolution, as defined previously, is a complex function depending on counting periods and statistics, sample and detector geometry, and the distribution and concentration of the NGR sources in the sample. The total NGR count rate of a specific radioactive horizon should vary as the horizon approaches and then passes the scintillating detectors positioned in the center of the sampling chamber because the fall-off of gamma rays away from the source is exponential. Maximum resolution is theoretically possible down to the $3-$ in. $(7.6-\mathrm{cm})$ width of the NaI scintillating detectors. However, because the maximum difference in detectable gamma rays from the edge to center of the MST NGR sample chamber is probably only $15 \%$ (cf. Rider, 1986), only very thin horizons with NGR emissions vastly different than the surrounding core can be identified. Furthermore, whereas normal counting statistics (30-60 s) can erode the theoretical difference to within $5 \%$, we feel that sampling increments shorter than $30 \mathrm{~cm}$ are likely to add false resolution to MST NGR data.

During Leg 150, NGR data required significant volumetric corrections as a result of pervasive edge and narrow-diameter effects. Because application of the volumetric correction requires us to assume NGR emissions are homogeneous over the length of one test ( 30 $\mathrm{cm}$ ), we could not measure NGR emissions that were statistically significant from sampling increments less than the $30-\mathrm{cm}$ chamber length. Our sampling interval, however, clearly satisfied the aforementioned goals of MST NGR logging for Leg 150.

One potential benefit of sampling increments less than $30 \mathrm{~cm}$ in length lies in the area of NGR statistical confidence. Because the MST NGR apparatus scans approximately $30 \mathrm{~cm}$ during each test, statistical confidence could be added by shortening the sampling intervals to less than $30 \mathrm{~cm}$, oversampling the test interval, and then applying an averaging filter to the results. This will reduce the statistical uncertainty but increase the time required to analyze a core. As we could not afford the incremental time, we used a $40-\mathrm{cm}$ sampling interval on all tests subsequent of Hole 904A.

\section{MST NGR to NGT Calibration}

Standardized MST NGR records are needed for the empirical determination of shale volume and the correlation of core to downhole logs using NGR records. The latter consideration is exemplified by comparing Figures 4A, 4B, and 4C. Note how the "counts" scales of the MST NGR and NGT records were adjusted to make the core and log data comparable. Although these adjustments are permissible in this hole because of superb core recovery, they would be inappropriate in holes with poor core recovery and noisy NGR signals where many possible correlations of peaks and troughs may occur. Therefore, to allow correlation of cores to downhole logs by depth shifting the core data, amplitudes of NGR variations must be comparable between the two data sets.

Downhole logging GAPI units are well established throughout the downhole logging industry and serve as the standard for core-log correlation. Obviously, the MST NGR device cannot be calibrated like downhole tools in the University of Houston test pit. Therefore, we calibrated the MST NGR detector to the only available standard: the downhole Schlumberger NGT log. Although the NGT sonde possesses its own imprecisions and differences exist between the tool designs and sampling volumes of the MST NGR and NGT devices, it is the only available medium between the MST NGR data and the international NGR standard of the API. Therefore, in the absence of any other standard, we assumed the cumulative error of calibrating the MST NGR response to the Schlumberger NGT is negligible and proceeded with calibrating the MST NGR device.

We calibrated MST NGR to NGT data by selecting and cross-plotting intervals from Holes 904A and 906A that represented the total range of NGR emissions seen during Leg 150, exhibited core-log depth correlation within $1 \mathrm{~m}$, and had log caliper and tension logs indicating good hole conditions. Because core and downhole log signals were based on different sampling intervals, we fit curves to both data sets using weighted least-squares and resampled both records at similar $(1 \mathrm{~m})$ intervals. A cross-plot of the two data sets (Fig. 5) shows the simple linear relationship between data from the NGT and the MST NGR. For the range of NGR emissions observed during Leg 150, the correction of MST NGR output to calibrated GAPI units of a Schlumberger NGT is

$$
\operatorname{NGR}(\text { GAPI })=12+2.12 \times \operatorname{NGR}(\mathrm{cps})
$$

The goodness-of-fit $\left(r^{2}\right)$ is 0.91 . From visual inspection of the data, we observe that the relationship generally overestimates equivalent downhole measurements by $10 \%-15 \%$ below 40 GAPI and underestimates downhole measurements above 70 GAPI by a similar amount. We feel that these errors are probably caused by our linear approximation of the core and $\log$ data relationship and that this error is generally negligible. We stress that this relationship is good only for the lithotypes (e.g., argillaceous and/or glauconitic siltstones, biosiliceous claystones, chalks, etc.) recovered during Leg 150. Furthermore, the correlation is only valid when comparing the MST NGR to Schlumberger NGT downhole logging sonde \#1736.

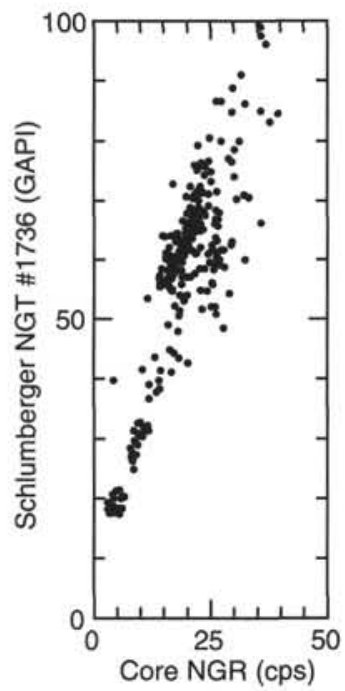

Figure 5. Cross-plot of core and downhole natural gamma-ray logs from Holes $904 \mathrm{~A}$ and $906 \mathrm{~A}$. Intervals had perfect core recovery and uniform (11 in.) open-hole conditions. Both data sets were curve-fit and resampled every $1 \mathrm{~m}$ before plotting. Number of comparative points is 240 . 


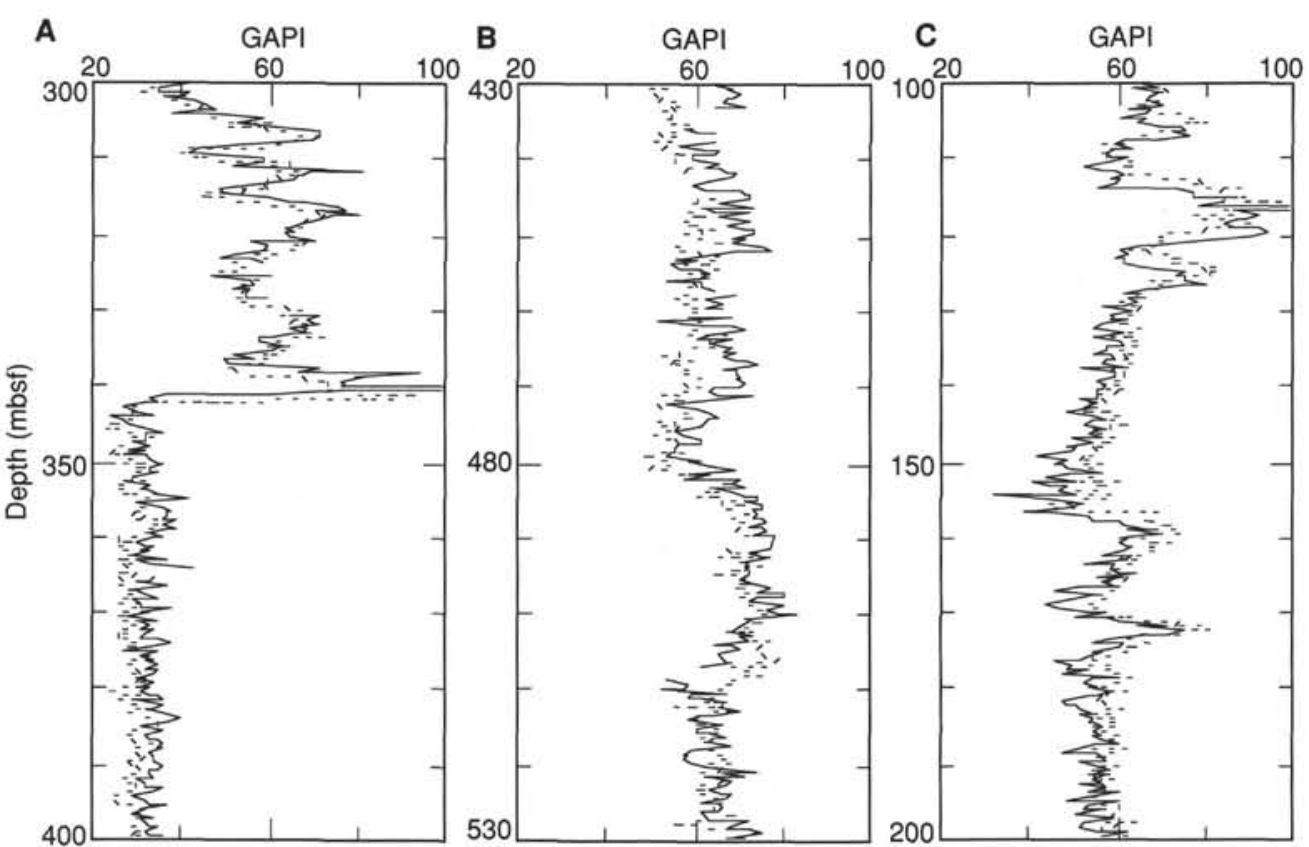

Figure 6. Comparison of corrected and calibrated MST NGR data (solid lines) plotted vs. corresponding downhole gamma-ray logs (dashed lines) for three selected intervals from Holes 904A (A), 905A (B), and 906A (C). Sections chosen for good overall core recovery and good hole-conditions. Depth corrections were not applied to the core data.

\section{RESULTS}

\section{Core to Downhole Log Comparison}

We found good to excellent MST NGR to downhole NGT log correlation. Presenting this correlation is problematic because the highly detailed and often subtle variations of NGR signals do not readily lend themselves to presentations at reduced scales. We therefore chose three 100-m intervals from Holes 904A, 905A, and 906A to exemplify the high degree of correlation between the shipboard and downhole NGR records. These data (Fig. 6) show MST NGR correlation to downhole NGT logs where (1) high core recovery and hence continuous MST NGR signal was obtained, and (2) the downhole caliper log shows the hole conditions to be good and hence no openhole log correction is necessary to the NGT downhole data from the porosity tool string (Schlumberger, 1986, chart POR-7). However, several inconsistencies appear. These are mostly artifacts of the random and discrete nature of natural gamma-ray emissions, the lessthan-perfect linear correction applied to the MST NGR data, and the slight offsets in core to log depths that we did not correct.

A good example of why such imperfect correlations are expected between MST NGR and NGT data is shown (Fig. 7) by two passes of Schlumberger NGT logging sonde \#1736 in Hole 904A after application of open-hole conditions. In this example, although the same tool sampled the same formation on the same day, different gammaray emissions were recorded due to the random and discrete nature of gamma-ray emissions. Notice, however, that the distribution of maximum and minimum values is consistent and that the maximum absolute difference in emissions is less than $15 \%$. These are the operational conditions we sought to replicate with our shipboard measurements. After review of preliminary NGR data from Leg 150 (Fig. 6), we feel we accomplished this goal.

\section{Applications}

It is not our goal to correct Leg 150 MST NGR data for interpretations of core-log correlations or lithologic compositions; however, we do illustrate the potential usefulness of MST NGR data by one example of core-log correlation and one of lithologic interpretation using MST NGR data generated during Leg 150.

In our first example, we used NGR data derived from cores of Hole 903D (where no downhole logs were obtained) and downhole logs from Hole $903 \mathrm{C}$ to show a possible correlation between these two locations (Fig. 8A). After making appropriate background-radiation and volumetric corrections, we applied the core-log fit calculated from other Leg 150 data (Eq. 2). The correlation of a high NGR spike at $910 \mathrm{~m}$ is apparent as is the correlation of several other subtle features (i.e., variations at 900,930 , and $940 \mathrm{mbsf}$ ). This example

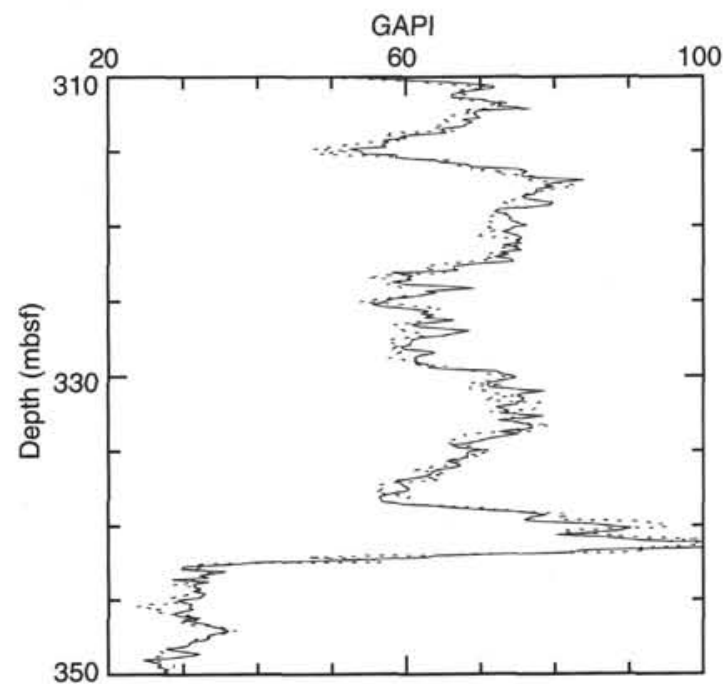

Figure 7. Downhole gamma-ray logs for an interval from Hole 904A exhibiting gamma-ray variability. The solid line represents the eccentrically positioned NGT during the porosity tool string logging run. The dashed line is the NGT record from the induction tool logging run corrected for open-hole conditions using the porosity tool string caliper log and Schlumberger open-hole correction chart POR-7. 


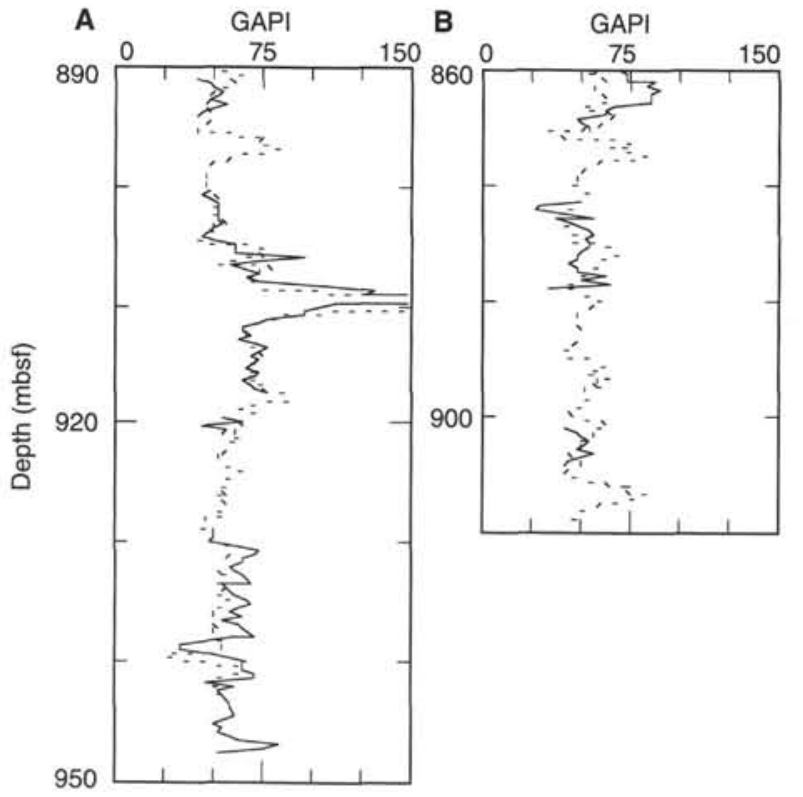

Figure 8. An example of the application of MST NGR data to core-log correlations for Site 903. A. Corrected and calibrated MST NGR data (solid line) from Hole 903D plotted vs. NGT data (dashed line) from Hole 903C. Depths appear to correlate to well within $1 \mathrm{~m}$ at distinctive intervals such as 910 or $940 \mathrm{mbsf}$. B. Interval in which data for MST NGR (solid line) and NGT (dashed line) show over $2 \mathrm{~m}$ of required depth-shifting. Given the excellent correlation between core and log data below $900 \mathrm{mbsf}$, the $2 \mathrm{~m}$ difference in data indicates a need for depth-shifting of the core data between 860 and $880 \mathrm{mbsf}$.

clearly demonstrates the close subsurface correlation between Holes $903 \mathrm{C}$ and 903D; mismatches of gamma-ray spikes in other parts of Hole 903D (Fig. 8B) can thereby be identified and appropriate coredepth corrections be made.

Our second example involves using shipboard NGR signals to provide additional mineralogical data not available from downhole logs. During Leg 150, useful downhole logging data were available only below the bottom of the drill pipe; thus, logs were rendered useless through the first $80-100$ mbsf of each hole. Although downhole NGT logging is theoretically possible through the pipe, NGT data acquired from inside the pipe requires additional corrections for type of steel, thickness, and seal with the formation. Although nomographs (cf. Lynch, 1962, p. 246) exist for these corrections, additional errors of significant magnitude are added and thus confidence in the quality of the data is drastically reduced.

To exemplify how shipboard NGR logging improves downhole NGT data, we corrected Hole 906A MST NGR data between 0 and 100 mbsf for background and volumetric effects, applied our core-log fit (Eq. 2), and plotted the resulting record along with the uncorrected downhole NGT data (Fig. 9). These records are dramatically different in their absolute and relative senses; particularly noteworthy is the cyclic drop in gamma-radiation centered about $37 \mathrm{mbsf}$ that is not reflected in the downhole data. This change may have significant implications of climatically or oceanographically induced compositional variations and thus, its characterization by shipboard MST NGR logging is of paramount importance to the goals of Leg 150.

\section{CONCLUSIONS AND RECOMMENDATIONS}

During Leg 150, we defined operational standards for the acquisition of NGR data from the MST system and procedures for correcting and calibrating the resulting data. This system uses scintillating gamma-ray detection to assess the combined elemental concentra-

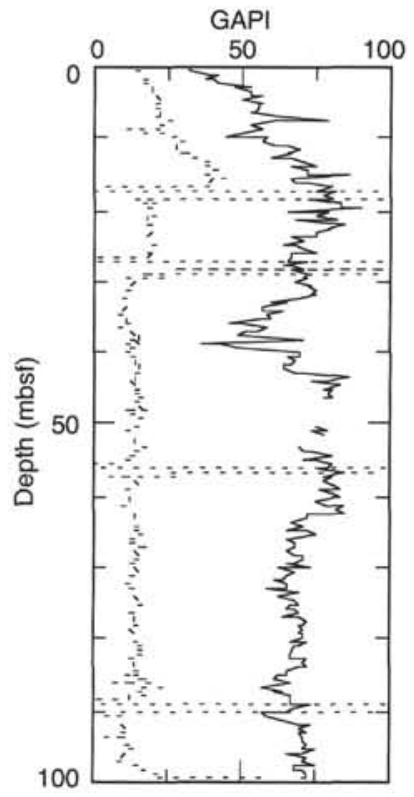

Figure 9. Comparison of corrected and calibrated data for MST NGR (solid line) and downhole NGT (dashed line) for the upper part of Hole 906A. The dramatically attenuated log data is caused by logging through the drill pipe. Also note that the NGT data lacks gamma-ray variability apparent in MST NGR data. Thus, the MST NGR data provides a superior tool for intersite correlation and lithologic studies through this interval.

tions of ${ }^{40} \mathrm{~K},{ }^{232} \mathrm{Th}$, and ${ }^{238} \mathrm{U}$. Results, some of which are only attainable through MST NGR logging, are potentially useful for core-tolog correlation, regional stratigraphic correlation, and mineralogical investigations.

With the present MST configuration (core stops for NGR measurement), the following procedures are recommended:

1. Check multichannel analysis software and sensor calibrations. Software calibrations need to be performed if the Europium peak of 1480.65 (MAESTRO library spectrum) does not fall on channel 993; sensor calibration is necessary if a characteristic peak, such as potassium ${ }^{40} \mathrm{~K}$ at $1.46 \mathrm{MeV}$, is divided in multiple peaks on the spectrum display. Standard measurements should be run routinely and saved with the data files for later verification of correct calibrations.

2. Measure background radiation routinely and record the data for subsequent NGR processing; this should be included as a regular, automated routine. Also, ask the drilling superintendent if doped $(\mathrm{KCl}$ or $\mathrm{BaSO}_{4}$ ) drilling muds were used during drilling or coring operations. These muds will alter true formational NGR emissions and consideration must be given to their presence before any interpretations are attempted.

3. Establish the minimum time required to obtain a statistically valid count on the least active material you want to measure; 20 s may be appropriate in terrigenous-rich muds, as shown for Leg 150 material, whereas a significantly longer period (2-3 min) may be needed for carbonates.

4. Establish the sampling interval. Maintaining core flow will limit the permissible number of samples per core. If a resolution similar to that of downhole logs is desired, 30 to $50 \mathrm{~cm}$ are appropriate (three measurements per section; note that first and last measurements should be at least $15 \mathrm{~cm}$ from section ends to minimize volume distortions). Sampling increments shorter than $30 \mathrm{~cm}$ will increase statistical confidence, but will probably not improve vertical resolution.

5. Make a "void log," which allows application of a volume correction to the measurements; void volumes can be estimated inde- 
pendently by review of the GRAPE record, or from observation of core photos. Narrow diameter cores can be measured using hand-held calipers.

6. Use the void log and Equation 1 to correct any volumetric inconsistencies in the MST NGR output. This correction is the most important data processing correction as even small volumetric changes can change the overall character of the MST NGR record. Remember that MST NGR output must be converted to a cps format before application of the correction.

7. Derive a relationship calibrating MST NGR data to downhole NGT data. The relationship derived for Leg 150 data (cf. Eq. 2) produced a record remarkably similar to the downhole tool in other intervals and holes. Although we only support the application of this fit for Leg 150, the procedure of determining similar relationships is outlined and recommended for future legs.

Should MST NGR be measured continuously in the future, logging speed must be established instead of sampling interval. For instance, with a time constant of $30 \mathrm{~s}$ (same as established above for Leg 150 terrigenous sediments) and a resolution of $46 \mathrm{~cm}$ (comparable to downhole logs; Borehole Research Group, 1990), $v=R / T=1.5$ $\mathrm{cm} / \mathrm{s}$; this speed is approximately the MST speed presently used. Logging of a section would take $100 \mathrm{~s}$, and a full core $(9.5 \mathrm{~m})$ would take $10.5 \mathrm{~min}$ - far less than other laboratory stations need to process a core. If the same resolution is desired with low-activity material, slower speeds are needed. Carbonate cores probably require $1-2 \mathrm{hr}$ per core. General core flow in the core lab can realistically tolerate a maximum of $1 \mathrm{hr}$ processing time at each station on high-recovery legs.

We also recommend that ODP pursue fabrication of three MST NGR test sections of at least $0.5-\mathrm{m}$ length with known concentrations of $\mathrm{K}$, Th, and U. These sections will provide for spectral NGR calibration and greatly enhance the usefulness of the MST NGR apparatus.

Properly correcting data provided a detailed gamma-ray record that will benefit the scientific goals of Leg 150 . We see no reason why future legs could not also realize similar benefits; therefore, we advocate the use of the MST NGR and our system of data processing on future ODP legs.

\section{ACKNOWLEDGMENTS}

We wish to thank ODP and the co-chiefs of Leg 150 for allowing us the opportunity to test and optimize the MST NGR apparatus. We are grateful to C. Fulthrope, J. Lorenzo, and A. Vecsei as well as to T. Kimura and other ODP Marine Laboratory Specialists for operating the NGR device and keeping it running despite often trying conditions. Advice and assistance in electronic and software questions by R. Current and E. Garrett are acknowledged as well. Thoughtful reviews were provided by K.M. Bohacs, K. Moran, and J.R. Schwalbach.

\section{REFERENCES *}

Belknap, W.B., Dewan, J.T., Kirkpatrick, C.V., Mott, W.E., Pearson, A.J., and Rabson, W.R., 1959. API calibration facility for nuclear logs. Drill. and Prod. Prac.

Borehole Research Group, 1990. Ocean Drilling Program Logging Manual: Palisades, NY (Lamont Doherty Geological Observatory).

Dewan, J.T., 1983. Essentials of Modern Open-Hole Log Interpretation: Tulsa (PennWell).

Evans, H.B., and Lucia, J.A., 1970. Natural gamma radiation scanner. In Peterson, M.N.A., Edgar, N.T., et al., Init. Repts. DSDP, 2: Washington (U.S. Govt. Printing Office), 458-460.

Hearst, J.R., and Nelson P.H., 1985. Well Logging for Physical Properties: New York (McGraw-Hill).

Lynch, E.J., 1962. Formation Evaluation: New York (Harper and Row).

Paulus, F.J., 1972. Leg 11 measurements of physical properties in sediments of the western North Atlantic and their relationship to sediment consolidation. In Hollister, C.D., Ewing, J.I., et al., Init. Repts. DSDP, 11: Washington (U.S. Govt. Printing Office), 667-722.

Rider, M.H., 1986. The Geologic Interpretation of Well Logs: London (Blackie/Halsted Press).

Schlumberger, 1986. Log Interpretation Charts: New York (Schlumberger).

Serra, O., 1984. Fundamentals of Well Log Interpretation: Amsterdam (Elsevier).

Serra, O., Baldwin, J., and Quiren, J., 1980. Theory, interpretation and practical applications of natural gamma-ray spectroscopy. Trans. SPWLA 21 st Annu. Logging Symp., Q1-Q30.

Wahl, J.S., 1983. Gamma ray logging. Geophysics, 48:1536-1550.

* Abbreviations for names of organizations and publications in ODP reference lists follow the style given in Chemical Abstracts Service Source Index (published by American Chemical Society).

Ms 150IR-105 